\title{
Hubungan Faktor Sociodemographic Dengan Depresi Postpartum Di Rumah Sakit Daerah
}

\section{Banjarmasin}

\author{
Winda Ayu Fazraningtyas ${ }^{1 *}$ \\ ${ }^{1}$ Program Studi Profesi Ners, Fakultas Kesehatan, Universitas Sari Mulia \\ *correspondence author: HP: +6281357430301 \\ E-mail: ns.winda26@gmail.com/windaayu@unism.ac.id
}

\begin{abstract}
Abstrak
Latar Belakang: Perempuan mengalami perubahan peran pada ibu hamil mulai dari status masih sendiri menjadi menikah dan kemudian menjadi seorang ibu. Selain itu, kesehatan mental merupakan hal yang penting untuk diketahui dan dimonitor, tetapi sering dilupakan dalam kesehatan reproduksi.

Tujuan: Penelitian ini bertujuan untuk menentukan dan menganalisis hubungan faktor sosiodemografik dengan depresi postpartum.

Metode: Penelitian ini merupakan penelitian kuantitatif dengan metode survey deskriptif. Sebanyak 88 responden terlibat dalam penelitian ini yang dirawat inap di Rumah Sakit Umum Daerah Ulin Banjarmasin dan Rumah Sakit Daerah Dr. H.M. Anshari Saleh Banjarmasin. Instrument yang digunakan dalam penelitian ini adalah Edinburgh Postnatal Depression Scale (EPDS), Beck Depression Inventory-II (BDI-II), and Postpartum Depression Risk Factors (PPDRF).

Hasil: Hasil dari penelitian ini menunjukkan tidak ada hubungan antara tingkat depresi dengan usia ibu, suku, status pernikahan, tingkat pendidikan tertinggi, pekerjaan, dan pendapatan.

Kesimpulan : Memiliki seorang anak dipertimbangkan sebagai sesuatu yang alamiah dan hal yang membahagiakan. Namun, masa transisi yang dialami oleh seorang perempuan menggambarkan kejadian yang penting dalam hidup dan meningkatkan kemungkinan untuk mengalami masalah psikologis.
\end{abstract}

Kata Kunci: faktor sosiodemografik, depresi postpartum 


\begin{abstract}
Background: There is a gradual change in the role of pregnant women as they move from single status to married state and, eventually, in becoming a mother. Nonetheless, mental health is important to note, but often a neglected component of reproductive health.

Objective : This study aimed to determine and analyze the socio-demographic factors associated with postpartum depression.

Methods This study used quantitative design with descriptive survey method. A total of 88 participants were included coming from Ulin General Hospital and Dr. H.M. Ansari Saleh General Hospital in Banjarmasin. Edinburgh Postnatal Depression Scale (EPDS), Beck Depression Inventory-II (BDI-II), and Postpartum Depression Risk Factors (PPDRF) checklist were used.

Results : It was found out that there is no significant relationship between the level of depression and maternal age, ethnicity, marital status, highest educational attainment, occupation, and gross monthly income.

Conclusion: Having a baby is usually considered to be a natural and joyous event. But, the transition to parenthood represents an important life event increasing vulnerability to psychological disorders.
\end{abstract}

Keywords: socio-demographic factors, postpartum depression

\section{Pendahuluan}

Kematian pada ibu hamil rentan terjadi dikarenakan ibu hamil tergolong dalam vulnerable group, dikarenakan ibu hamil mengalami perubahan fisiologis yang dialami selama masa kehamilan, baik secara fisik dan psikologis (Park et al., 2015; Josefsson, 2007). Semua perubahan yang terjadi ini pada umumnya dapat dilewati ibu dengan sukses. Namun, pada kenyataan tidak semua ibu mampu melewatinya, khususnya perubahan psikologis yang dialami oleh ibu. Perubahan psikologis pada masa kehamilan merupakan perubahan sikap dan perasaan tertentu dalam mengalami pada ibu hamil dan memerlukan adaptasi (Pillitteri, 2014). Disamping itu, terjadi perubahan peran pada ibu hamil yang sebelumnya menjalani fase sebagai anak kemudian menjadi istri dan kemudian harus siap menjadi seorang ibu.

Selain itu, perubahan bentuk tubuh yang dialami oleh ibu selama masa kehamilan juga mempengaruhi kondisi psikologis ibu melahirkan. Gangguan yang terjadi pada ibu hamil dan melahirkan dapat meliputi stress, konflik, regresi, cemas, labilitas emosi, 
ambivalensi, dan depresi (Hildayani, 2016). Depresi yang terjadi pada ibu ini dapat muncul pada periode postnatal ataupun postpartum. Depresi postpartum seperti pencuri yang mengambil kebahagiaan dan kasih sayang yang dirasakan ibu dan yang diberikan pada bayi baru lahir. Di samping itu, ibu dengan depresi postpartum juga merasakan kesulitan untuk melakukan dan menjalani aktivitas sehari-hari (American Psychological Association, 2017).

Kesehatan jiwa penting untuk diingat dan diketahui, tetapi sering terlupakan dalam kesehatan reproduksi (Humayun et al., 2013). Selain itu, penelitian tentang depresi postpartum yang dilakukan di Indonesia masih terbatas. Oleh karena itu, penelitian tentang depresi postpartum penting untuk dilakukan. Tujuan penelitian ini adalah untuk menentukan dan menganalisis faktor sosiodemografik yang berhubungan dengan depresi postpartum.

\section{Bahan dan metode}

Penelitian ini merupakan penelitian kuantitatif dengan metode survey deskriptif. Responden dalam penelitian ini adalah ibu postpartum yang dirawat inap di RSUD Ulin
Banjarmasin dan RSUD Dr. H.M. Ansari Saleh Banjarmasin yang diambil dengan purposive sampling dengan total responden sebanyak 88 responden. Penelitian ini dilaksanakan pada bulan Maret s.d. Mei 2018. Instrumen yang digunakan dalam penelitian ini adalah Edinburg Postnatal Depression Scale (EPDS), Beck Depression Inventory (BDI)-II, dan Postpartum Depression Risk Factors (PPDRF) checklist.

Teknik pengambilan data yang dilakukan pada penelitian ini meliputi 3 tahapan, yaitu tahapan pertama, kedua, dan ketiga. Tahapan pertama ini merupakan tahapan dimana peneliti menyiapkan semua persiapan yang terkait dengan penelitian, termasuk surat perizinan. Tahapan kedua adalah tahapan implementasi dari penelitian ini. Kemudian diakhiri dengan tahapan ketiga, yaitu tahapan interpretasi data yang meliputi tabulasi data dan analisis data.

Statistik deskriptif digunakan untuk mendeskripsikan faktor sosiodemografik dari responden dan tingkat depresi yang dialami oleh responden disajikan dalam bentuk distribusi frekuensi dan persentase. Analisis 
data yang digunakan dalam penelitian ini adalah uji $X^{2}$ dimana analisis ini digunakan untuk mengetahui hubungan tingkat depresi dan faktor sosiodemografik dari depresi postpartum. Level signifikansi $(\alpha)$ yang digunakan adalah 0.05 .

\section{Hasil}

Tabel 1 menunjukkan distribusi frekuensi dari faktor sosiodemografik yang meliputi usia ibu, suku, status pernikahan, pendidikan terakhir, dan penghasilan. Lebih lanjut, sebagian besar ibu postpartum berusia 26-30 tahun, yaitu sebesar 33\%. Mayoritas dari responden merupakan suku Banjar (89,9\%). Disamping itu, sebanyak $98,9 \%$ status pernikahan ibu postpartum yang dirawat inap di RSUD Ulin Banjarmasin dan RSUD Dr.

H.M. Ansari Saleh Banjarmasin adalah menikah. Pekerjaan dari responden adalah sebagian besar sebagai Ibu Rumah Tangga (83\%). Ditambah lagi lebih dari 50\% responden berpenghasilan kurang dari $\mathrm{Rp}$. 1.000.000,00 setiap bulannya.

\begin{tabular}{|c|c|c|}
\hline $\begin{array}{c}\text { Faktor } \\
\text { Sosiodemografik }\end{array}$ & $\begin{array}{c}\text { Frekuensi } \\
\text { (Responden) }\end{array}$ & $\begin{array}{c}\text { Persentase } \\
(\%)\end{array}$ \\
\hline \multicolumn{3}{|l|}{ Usia ibu } \\
\hline$\leq 20$ tahun & 8 & 9,10 \\
\hline $21-25$ tahun & 15 & 17,0 \\
\hline $26-30$ tahun & 29 & 33,0 \\
\hline $31-35$ tahun & 27 & 30,7 \\
\hline $36-40$ tahun & 8 & 9,10 \\
\hline$\geq 41$ tahun & 1 & 1,10 \\
\hline \multicolumn{3}{|l|}{ Suku } \\
\hline Banjar & 79 & 89,8 \\
\hline Madura & 6 & 6,80 \\
\hline Batak & 2 & 2,30 \\
\hline Jawa & 1 & 1,10 \\
\hline \multicolumn{3}{|l|}{ Status Pernikahan } \\
\hline Menikah & 87 & 98,9 \\
\hline Janda & 1 & 1,10 \\
\hline \multicolumn{3}{|l|}{ Pendidikan Terakhir } \\
\hline Sekolah Dasar & 17 & 19,3 \\
\hline SMP/SMA & 52 & 59,1 \\
\hline Diploma/Sarjana & 19 & 21,6 \\
\hline \multicolumn{3}{|l|}{ Pekerjaan } \\
\hline Ibu Rumah Tangga & 73 & 83,0 \\
\hline Karyawan Swasta & 13 & 14,8 \\
\hline Aparatur Sipil Negara & 2 & 2,30 \\
\hline \multicolumn{3}{|l|}{ Penghasilan } \\
\hline$<$ Rp. $1.000 .000,00$ & 49 & 55,7 \\
\hline $\begin{array}{l}\text { Rp. } 1.000 .000,00-\text { Rp. } \\
5.000 .000,00\end{array}$ & 36 & 40,9 \\
\hline$>$ Rp. $5.000 .000,00$ & 3 & 3,40 \\
\hline
\end{tabular}

Tabel 2. Distribusi frekuensi tingkat depresi responden

\begin{tabular}{lcc}
\hline Tingkat Depresi & Frekuensi & Persentase \\
\hline Ringan & 50 & 56,8 \\
Sedang & 23 & 26,1 \\
Berat & 15 & 17,0 \\
\hline
\end{tabular}

Tabel 2 menggambarkan distribusi frekuensi tingkat depresi yang dialami oleh responden, sebagian besar responden mengalami depresi ringan, dimana pada level ini depresi yang dialami ibu masih dapat ditangani dengan treatment yang sederhana, sedangkan sebanyak $26,1 \%$ responden mengalami depresi pada tingkat sedang dan $17 \%$ responden mengalami depresi berat. Hal 
ini patut untuk diwaspadai karena depresi pada tingkat sedang sudah menunjukkan gejalagejala kecemasan yang mengganggu kegiatan sehari-hari. Ditambah lagi, depresi pada tingkat berat memerlukan penanganan khusus dari psikiatris (Cox, et al., 1987).

Tabel 3. Analisis data hubungan faktor sosiodemografik dengan tingkat depresi postpartum

\begin{tabular}{lcc}
\hline Faktor Sosiodemografik & $\begin{array}{c}\boldsymbol{\chi} \mathbf{2} \text { value } \\
\mathbf{d f}=\mathbf{1 0}\end{array}$ & P-value \\
\hline Usia ibu & 12.265 & 0.268 \\
Suku & $1.907^{\mathrm{a}}$ & 0.928 \\
Status pernikahan & $0.769^{\mathrm{a}}$ & 0.681 \\
Pendidikan tertinggi & $2.660^{\mathrm{a}}$ & 0.616 \\
Pekerjaan & $1.761^{\mathrm{a}}$ & 0.780 \\
Penghasilan & $1.761^{\mathrm{a}}$ & 0.780 \\
\hline
\end{tabular}

Pada tabel 3 menggambarkan analisis

data hubungan faktor sosiodemografik dengan tingkat depresi postpartum yang dialami oleh responden. Melalui tabel tersebut, diketahui bahwa tidak hubungan yang signifikan antara faktor sosiodemografik yang meliputi usia ibu, suku, status pernikahan, pendidikan terakhir, pekerjaan, dan penghasilan.

\section{Pembahasan}

Pada usia ibu, diketahui tidak ada hubungan yang signifikan dengan depresi postpartum. Hasil ini sejalan dengan penelitian yang dilakukan oleh McCahon, et al. (2015) yang menginvestigasi bahwa usia tidak dapat memprediksikan kejadian depresi selama periode postpartum. Hal ini dikarenakan tingkat maturitas seseorang tidak didasarkan pada usia orang tersebut, tetapi berbagai faktor yang mempengaruhi, seperti pola pikir, pengalaman yang didapatkan selama menjalani kehidupan, dan lainnya. Di samping itu, periode kehamilan dan persalinan seorang ibu akan lebih erat terkait dengan kesiapan mental ibu untuk menjalani peran barunya sebagai seorang ibu (Kusuma, 2017; Bottino et al., 2012). Bagaimanapun juga, usia berhubungan dengan gaya hidup dan kedewasaan emosional dari orang tersebut (de Castro, et al., 2011). Selain itu, menurut American College of Obstetricians and Gynecologists (2014) menunjukkan bahwa usia di bawah 35 tahun memiliki kemampuan dan waktu konsepsi yang baik untuk kehamilan. Pada usia 26-35 tahun, seorang ibu diharapkan siap secara mental untuk merawat anak-anak (Tough et al., 2007).

Mayoritas responden berasal dari Suku Banjar, yaitu sebanyak 89,9\%. Suku Banjar menerapkan nila-nilai budaya dalam kehidupan sehari-hari. Nilai-nilai budaya 
meliputi hubungan manusia dengan Tuhan, hubungan manusia dengan alam, hubungan manusia dengan manusia dan hubungan manusia dengan diri sendiri. Implikasi nilainilai budaya dari hubungan manusia dengan kemanusiaan termasuk nilai-nilai persaudaraan, bantuan, dan kemampuan beradaptasi. Konsep nilai yang mendorong setiap ibu untuk berjuang adalah karena ibu menganggap bahwa akan selalu ada orang yang akan membantu ketika ibu tersebut mengalami kesulitan (Istiqomah \& Setyobudihono, 2014).

Suku Banjar sendiri mengembangkan sistem budaya, sistem sosial dan materi budaya yang berkaitan dengan agama, melalui berbagai proses adaptasi, akulturasi, dan asimilasi. Namun demikian, pandangan atau pengaruh Islam lebih dominan dalam kehidupan budaya Banjar, hampir identik dengan Islam, meskipun dalam kehidupan sehari-hari, masih ada unsur-unsur asal budaya, Hindu, dan Budha (SatelitPost, 2018).

Tidak ada hubungan yang signifikan antara status pernikahan dan tingkat depresi postpartum. Status suatu hubungan tidak hanya dituntut dalam pernikahan tetapi juga kualitas hubungan yang dibangun. Kualitas hubungan yang baik akan memberikan rasa aman bagi ibu karena tidak ada kecurigaan dalam hubungan rumah tangga. Meskipun demikian, pasangan juga dapat menjadi sumber stres, tergantung pada kualitas hubungan. Pernikahan melambangkan komitmen yang kuat untuk suatu hubungan dan orang yang menikah pada rata-rata hidup bersama yang berkualitas (Bener, et al., 2012; Akincigil, et al., 2010).

Selain itu, diketahui pula tidak ada hubungan antara tingkat depresi postpartum dengan tingkat pendidikan responden. Kusuma (2017) menginvestigasi bahwa tidak ada hubungan yang signifikan antara tingkat depresi dan pendidikan. Ibu dengan tingkat pendidikan rendah dan tinggi memiliki kemungkinan yang sama untuk mengalami depresi postpartum. Namun, bagi ibu yang memiliki tingkat pendidikan lebih tinggi dalam menangani masalah depresi postpartum lebih mudah daripada ibu yang memiliki tingkat pendidikan yang lebih rendah karena ibu dengan tingkat pendidikan yang lebih tinggi 
cenderung lebih berpikiran terbuka.

Kurangnya korelasi antara tingkat pendidikan

dan depresi postpartum mungkin disebabkan

oleh kenyataan bahwa saat ini perempuan

dengan mudah mengakses informasi kesehatan

dari berbagai media; yaitu, internet, buku,

surat kabar, dll. (Kusuma, 2017).

Salah satu masalah yang dihadapi dalam

hal pendidikan adalah tingginya biaya kuliah

dan juga merupakan salah satu faktor yang

menyebabkan orang enggan untuk

melanjutkan pendidikan mereka (Aini, 2017).

Selain itu, perempuan tidak perlu melanjutkan

studi ke jenjang yang lebih tinggi karena stigma yang mengatakan bahwa jika seorang

wanita memiliki tingkat pendidikan yang tinggi, akan sulit untuk menemukan seorang suami (Rangkuti, 2015). Selain itu, wanita dengan tingkat pendidikan yang lebih tinggi dapat memicu perkelahian dalam keluarga yang juga merupakan salah satu faktor yang menyebabkan wanita tidak melanjutkan pendidikan tinggi (Rossa \& Nodia, 2018).

Di samping itu juga, tidak ada hubungan antara pekerjaan dengan tingkat depresi postpartum pada responden. Status ibu yang bekerja sebagai pegawai pemerintah dan swasta memiliki penghasilan tetap, sementara ibu rumah tangga hanya melakukan tugas rutin dan kegiatan sehari-hari di rumah. Pekerjaan ini cenderung tidak mempengaruhi kondisi psikologis ibu nifas karena status pekerjaan ibu lebih berpengaruh pada peningkatan pendapatan keluarga. Tingkat kecemasan ibu yang menganggur cenderung dikaitkan dengan dana yang terbatas ketika ibu membutuhkan layanan kesehatan yang berbeda dengan ibu yang bekerja yang mungkin memiliki dana yang lebih baik untuk melakukan perawatan kesehatan (Hutagaol, 2010).

Ditambah lagi, tidak ada hubungan yang signifikan antara tingkat depresi postpartum dengan penghasilan. Hal ini dapat terjadi karena peserta mendapat dukungan dari keluarga; jadi, untuk perawatan peserta, anakanak mendapatkan dukungan keuangan dari keluarga sebagai imbalan. Selain itu, keberadaan asuransi kesehatan yang disediakan oleh pemerintah Indonesia juga memberikan ketenangan bagi para peserta selama rawat inap. Sebaliknya, Manjunath, dkk. (2011) melaporkan bahwa ada hubungan 
yang signifikan antara tingkat depresi dan

pendapatan keluarga, dikarenakan

bertambahnya anggota baru ke keluarga akan

memberikan tekanan yang besar secara

finansial.

\section{Ucapan terima kasih}

Penelitian ini didukung penuh oleh

Universitas Sari Mulia di Banjarmasin. Selain

itu, peneliti juga mengucapkan terima kasih

atas izin yang telah diberikan oleh Direktur

RSUD Ulin Banjarmasin dan Direktur RSUD

Dr. H.M. Ansari Saleh Banjarmasin sehingga

penelitian ini dapat terlaksana.

\section{Daftar Pustaka}

Aini, R. 2017. Mahalnya Biaya Pendidikan di Indonesia. Retrieved from https://www.kompasiana.com/rokyalaini /mahalnya-biaya-pendidikan-di indonesia_5917151fc5afbd54415ebacf.

Akincigil, A., Munch, S., \& Niemczyk, K.C. (2010). Predictors of maternal depression in the first year postpartum: marital status and mediating role of relationship quality. Social Work in Health Care, 49, 227-244.

American College of Obstetricians and Gynecologists Committee on Gynecologic Practice and PracticeCommittee. (2014). Female agerelated fertility decline. Committee Opinion No. 589. Fertil Steril, 101, 6334.
American Psychological Association (APA). (2017). What is postpartum depression \& anxiety? Retrieved from www.apa.org/pi/women/resources/report s/postpartum depression.aspx.

Bener, A., Burgut, F.T., Ghuloum, S., \& Sheikh, J. (2012). A study of postpartum depression in a fast-developing country: prevalence and related factors. Int'l. J. Psychiatry in medicine, 43(4), 325-337.

Bottino, M.N., Reichenheim, M.E., Nadanovsky, P., Moraes, C.L., \& Lobato, G. (2012). Reappraising the relationship between maternal age and postpartum depression according to the evolutionary theory: Empirical evidence from a survey in primary health services. Journal of Affective Disorders, 142, 219-224.

Cox, J.L., Holden, J.M., \& Sagovsky R. (1987). Detection of postnatal depression: Development of the 10-item Edinburg Postnatal Depression Scale. British Journal of Psychiatry, 150, 782-786.

deCastro, F., Hinojosa-Ayala, N., \& Hernandez-Prado, B. (2011). Risk and protective factors associated with postnatal depression in Mexican adolescents. Journal of Psychosomatic Obstetrics \& Gynecology, 32(4), 210217.

Hildayani, R. (2016, December 3). Manajemen kesehatan mental sebelum dan saat kehamilan. Paper presented at Symposium Preconception and Pregnancy Nutrition for Healthy Pregnancy Outcomes.

Humayun, A., Haider, I.I., Imran, N., Iqbal, H., \& Humayun, N. (2013). Antenatal depression and its predictors in Lahore, Pakistan. East Mediterr Health J., 19(4), 327-332.

Hutagaol, E.T. (2010). Efektivitas Intervensi Edukasi pada Depresi Postpartum. [Thesis]. Depok: Fakultas Ilmu Keperawatan Universitas Indoesia. 
Istiqomah, E., \& Setyobudihono, S. (2014). Nilai budaya masyarakat Banjar Kalimantan Selatan: Studi indigenous. Jurnal Psikologi Teori dan Terapan, 5(1), $1-6$.

Josefsson, A., Larsson, C., Sydsjo, G., \& Nylander, P.O. (2007). Temperament and character in women with postpartum depression. Arch Womens Ment Health, 10, 3-7.

Kusuma, P.D. (2017). Karakteristik penyebab terjadinya depresi postpartum pada primipara dan multipara. Jurnal Keperawatan Notokusumo, 5(1), 36-45.

Manjunath, N.G., Venkatesh, G., \& Rajanna. (2011). Postpartum blue is common in sociality and economically insecure mothers. Indian J Community Med, 36(3), 231-233.

McMahon, C.A., Jacky Boivin, Frances L. Gibson, Karin Hammarberg, Karen Wynter, and Jane R.W. Fisher. 2015. Older Maternal Age and Major Depressive Episodes in the First Two Years After Birth: Findings from the Parental Age and Transition to Parenthood Australia (PATPA) Study. Journal of Affective Disorders, 175, 454 462.

Park, J.H., Karmaus, W., \& Zhang, H. (2015). Prevalence of and risk factors for depressive symptoms in Korean women throughout pregnancy and in postpartum depression. Asian Nursing Research, 9, 219-225.

Pillitteri, A. (2014). Maternal \& child health nursing: Care of the childbearing \& childrearing family (7th ed.). Philippines: Lippincott Williams \& Wilkins.
Rangkuti, A.F. 2015. Bersekolahlah tinggitinggi, maka jodohmu akan jauh. Retrieved from https://www.kompasiana.com/annisa_ra ngkuti/bersekolah-lah-tinggi-tinggimaka-jodohmu-akanjauh 5510aac6813311d438bc6d59.

Rossa, V., \& Nodia, F. (2018). Alasan banyak perempuan enggan berpendidikan lebih tinggi. Retrieved from https://www.suara.com/lifestyle/2018/01 31/102904/alasan-banyak-perempuanenggan-berpendidikan-lebih-tinggi.

SatelitPost. (2018). Mengenal budaya suku banjar. Retrieved from https://satelitpost.com/redaksiana/menge nal-budaya-suku-banjar.

Tough S, Tofflemire K, Benzies K, Fraser-Lee N, Newburn-Cook C. (2007). Factors influencing childbearing decisions and knowledge of perinatal risks among Canadian men and women. Matern Child Health J, 11, 189-98. 